\title{
The Possibility of New Ordering Reaction in Cu-50 mass\% Au Alloy
}

\author{
Djamel Hamana, Loubna Chetibi, Leila Amiour and Faouzi Hanini \\ Phases Transformations Laboratory, Mentouri University of Constantine, Ain El Bey Road, Constantine 25000, Algeria
}

\begin{abstract}
Among the large number of superlattices, there is a special group which may be classified as long period superlattices, the copper-gold system provides a classical example of such structure. Despite that historically, the copper-gold alloys containing about 25 atom percent gold were among the first investigated alloys, it still represents a subject of numerous studies. In the present work, we study all the possible phase transitions in the binary intermetallic alloy $\mathrm{Cu}_{3} \mathrm{Au}$ using differential scanning calorimetry (DSC) and differential dilatometry. A new important anomaly due certainly to a new ordered reaction has been detected at low temperature range by these two methods. To confirm this new reaction, we have used other techniques as high resolution transmission electron microscopy (HRTEM), electrical resistivity and microhardness measurements. The kinetics parameters as activation energy $E_{\text {act }}$ and Avrami exponent $n$ have also been calculated respectively by Starink and John Mehl Avrami Kolmogorov (JMAK) methods. [doi:10.2320/matertrans.M2010332]
\end{abstract}

(Received September 28, 2010; Accepted February 16, 2011; Published May 18, 2011)

Keywords: phase transition, copper-gold alloy, differential scanning calorimetry, high resolution transmission electron microscopy

\section{Introduction}

In the solid solution, the distribution of atoms is generally statistical and at random, but under certain conditions these solutions could be ordered. ${ }^{1)}$ The order-disorder transition takes a very important place because of its influence on the physical and mechanical characteristics of metals. Since its observation on $1934^{2}$ in $\mathrm{Cu}-\mathrm{Zn}$ alloys (brass), this transition which is expressed by the existence of one state in which atoms are ordered in crystal lattice, has been widely studied. $^{3-7)}$ On the basis of X-ray diffraction, it has been noticed that below certain transition temperature, the atoms can be ordered on two sublattices which interpenetrate, i.e. the atoms of every type have tendency to take specific places in the crystal lattice by changing their position. ${ }^{1,2)}$

The ordered phase is characterized by a long-range-order parameter which vanishes in the disordered phase. Due to the symmetry breaking associated with an order-disorder transition, an ordering process leads to the coexistence of different variants (or domains) of the same ordered phase. ${ }^{8)}$

The $\mathrm{Cu}-\mathrm{Au}$ system provides a classical example of such structures. $\mathrm{Cu}$ and $\mathrm{Au}$ atoms form a continuous series of solid solutions at high temperature, but several superlattices exist at low temperatures, near compositions $\mathrm{Cu}_{3} \mathrm{Au}, \mathrm{CuAu}$, $\mathrm{CuAu}_{3} .{ }^{9)} \mathrm{A}$ recent study of $\mathrm{CuAu}$ alloy has shown an important new anomaly at lower temperature, ${ }^{10)}$ in addition to the known phases existing in $\mathrm{CuAu}$ alloy: $\mathrm{CuAuI}$ and $\mathrm{CuAu}$ II ordered phases, and $\mathrm{A} 1$ disordered phase.

In this work we focus on the $\mathrm{Cu}_{3} \mathrm{Au}$ alloy which has been the subject of numerous investigations due to its relationship with materials having improved electronic properties for technological applications including catalysis, coating and high devices. ${ }^{11)}$

The $\mathrm{Cu}_{3} \mathrm{Au}$ ordered phase is formed in $\mathrm{L}_{2}$ structure from the disordered fcc solution (A1) in the temperature range below $390^{\circ} \mathrm{C}$. The order-disorder transition between $\mathrm{A} 1$ and $\mathrm{L}_{2}$ is classified as first order order-disorder transition. ${ }^{12)}$

This work attempts to interpret dilatometric and calorimetric anomalies occurring during continuous heating of a homogenized and quenched $\mathrm{Cu}-50$ mass\% $\mathrm{Au}$ alloy and to try to detect a new reaction at low temperature, by using differential scanning calorimetry (DSC) and differential dilatometric analysis; other experimental techniques as high resolution transmission electron microscopy (HRTEM), and resistivity and microhardness measurements will be used. Moreover a detailed kinetics study of this new reaction will be done.

\section{Experimental Procedure}

We have used in this study the $\mathrm{Cu}-50$ mass\% $\mathrm{Au}$ alloy corresponding to intermetallic $\mathrm{Cu}_{3} \mathrm{Au}$ alloy (more exactly $\mathrm{Cu}_{0,756} \mathrm{Au}_{0,244}$, elaborated by melting of pure elements $(99,999 \%)$; the composition was checked by X-ray diffraction analysis and $\mathrm{X}$ ray-fluorescence.

For the dilatometric analysis, a DI24 Adamel Lhomergy dilatometer connected to a computer has been used. The samples were prepared as parallelepiped pieces of $25 \mathrm{~mm}$ length, $5 \mathrm{~mm}$ width, and $5 \mathrm{~mm}$ thickness.

For the differential calorimetric analysis (DSC), a SETARAM DSC 131 analyzer connected to a computer has been used. The samples were in a cylindrical shape ( $2 \mathrm{~mm}$ length and $5 \mathrm{~mm}$ diameter) corresponding to a weight of approximately $300 \mathrm{mg}$. In the both cases tests were performed under Argon.

The dilatometric and calorimetric cycle consists of heating from room temperature to $500^{\circ} \mathrm{C}$, holding of $1 \mathrm{~min}$ and cooling down to room temperature with the same rate.

The samples have been undergone two kinds of heat treatments; firstly they were homogenised under primary vacuum for $1 \mathrm{~h}$ at $500^{\circ} \mathrm{C}$, quenched in water, then heated in DSC and DI 24 up to $500^{\circ} \mathrm{C}$ with several rates $(v=5,7,9,10$, $15,20,25$ and $30^{\circ} \mathrm{C} . \mathrm{min}^{-1}$ ); secondly, the samples were homogenised under vacuum for $1 \mathrm{~h}$ at different temperatures $\left(450,500,700,750,800\right.$ and $\left.850^{\circ} \mathrm{C}\right)$ by applying the thermal cycle in DSC and DI24 quoted above but with a constant rate $v=5^{\circ} \mathrm{C} \cdot \mathrm{min}^{-1}$.

HRTEM specimens were prepared by Ion Slicer (Em09100) and were examined in JEM-2100 Lab 6 High 


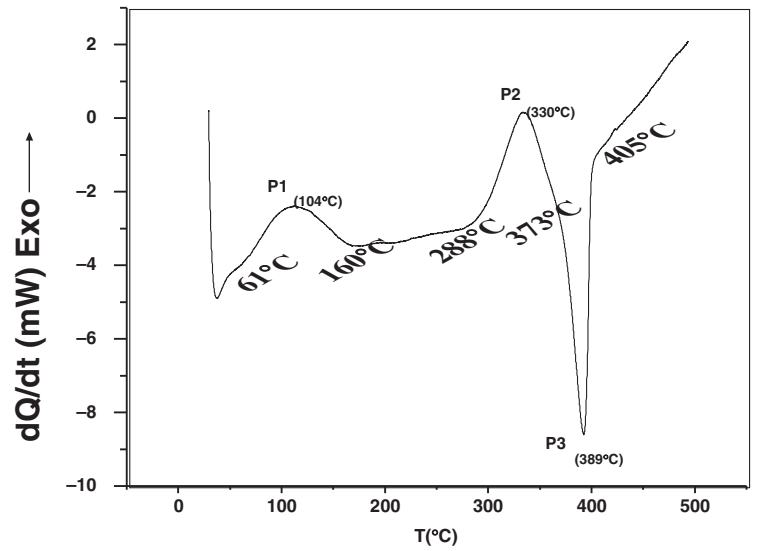

Fig. 1 DSC curve of $\mathrm{Cu}_{3} \mathrm{Au}$ alloy homogenised $1 \mathrm{~h}$ at $500^{\circ} \mathrm{C}$ and water quenched.

Resolution Transmission Electron microscope operating at $200 \mathrm{KV}$.

The resistivity measurements were made using direct current potentiometric method with two probes.

The microhardness tests were made using a Zwick Vickers hardness indenter with a $300 \mathrm{mg}$ load.

\section{Results and Discussion}

\subsection{DSC results}

The DSC scan obtained during heating $\left(V=3^{\circ} \mathrm{C} \cdot \mathrm{min}^{-1}\right)$ of the sample homogenised under vacuum and water quenched (Fig. 1), reveals two exothermic peaks P1 and P2 in the temperature range $\left[61-160^{\circ} \mathrm{C}\right]$ and $\left[288-373^{\circ} \mathrm{C}\right]$ respectively and an endothermic one P3 between $373^{\circ} \mathrm{C}$ and $405^{\circ} \mathrm{C}$.

- the appearance of $\mathrm{P} 1$ is probably linked to one phase transformation though the $\mathrm{Cu}-\mathrm{Au}$ phase diagram, does not show any phases at this range of temperature. This first reaction is probably identical to that found recently in the equiatomic $\mathrm{CuAu}$ alloy. ${ }^{10)}$

- P2 is certainly due to the formation of $\mathrm{Cu}_{3} \mathrm{Au}$ ordered phase,

- P3 is attributed to the order-disorder transformation from $\mathrm{Cu}_{3} \mathrm{Au}$ ordered phase to the disorder solid solution.

\subsection{Dilatometry study}

The derivative curve of the heating segment of homogenised and water-quenched alloy with the same heating rate $\left(3^{\circ} \mathrm{C} \cdot \mathrm{min}^{-1}\right)$, is shown in Fig. 2. One can observe the presence of the first reaction detected already by DSC analysis, and characterised here by a contraction at lower temperature with a minimum $\mathrm{P} 1$ situated at $123^{\circ} \mathrm{C}$, before the contraction peak P2 corresponding to the $\mathrm{Cu}_{3} \mathrm{Au}$ ordered phase formation and situated between $274^{\circ} \mathrm{C}$ and $368^{\circ} \mathrm{C}$, followed by an important expansion $\mathrm{P} 3$ linked to the decrease of the ordering of $\mathrm{Cu}_{3} \mathrm{Au}$ phase and its transformation to the A1 disordered phase.

\subsection{Heating rate effect}

The variation of the heating and cooling rate during DSC and dilatometric tests (for DSC: $v=5,7,9,10,15,20,25$

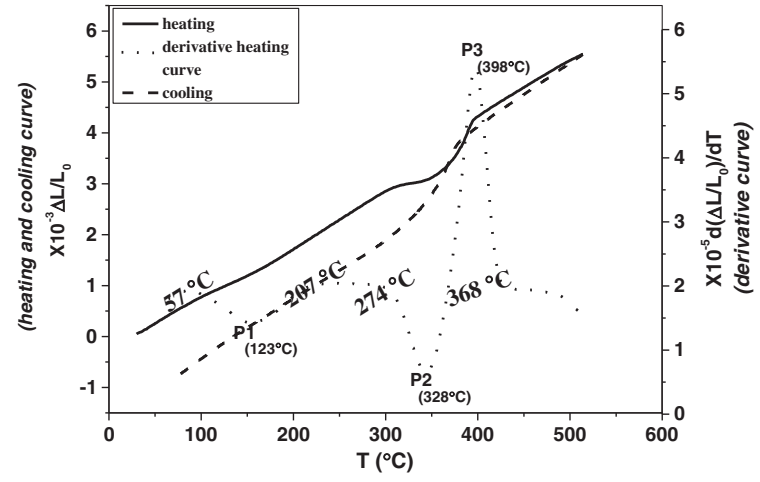

Fig. 2 Dilatometric curve of $\mathrm{Cu}_{3} \mathrm{Au}$ alloy homogenised $1 \mathrm{~h}$ at $500^{\circ} \mathrm{C}$ and water quenched.

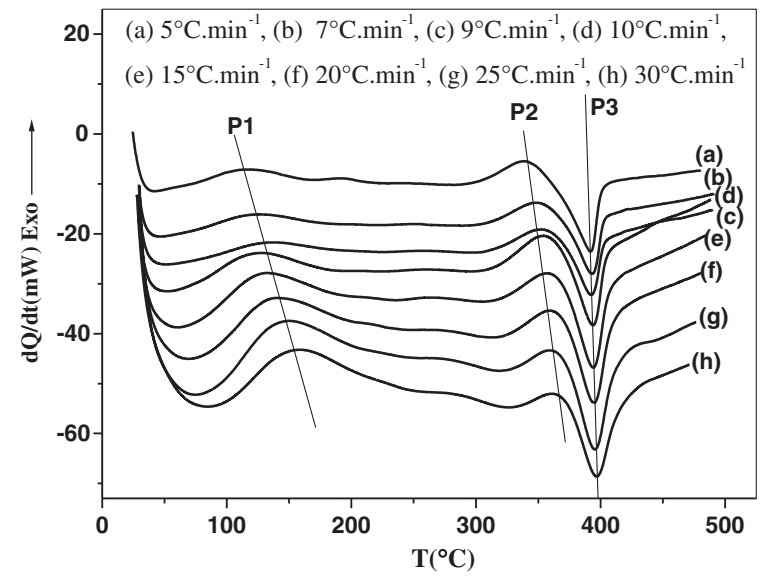

Fig. 3 DSC heating curves during of samples homogenised $1 \mathrm{~h}$ at $500^{\circ} \mathrm{C}$ and water quenched then heated with different rates.

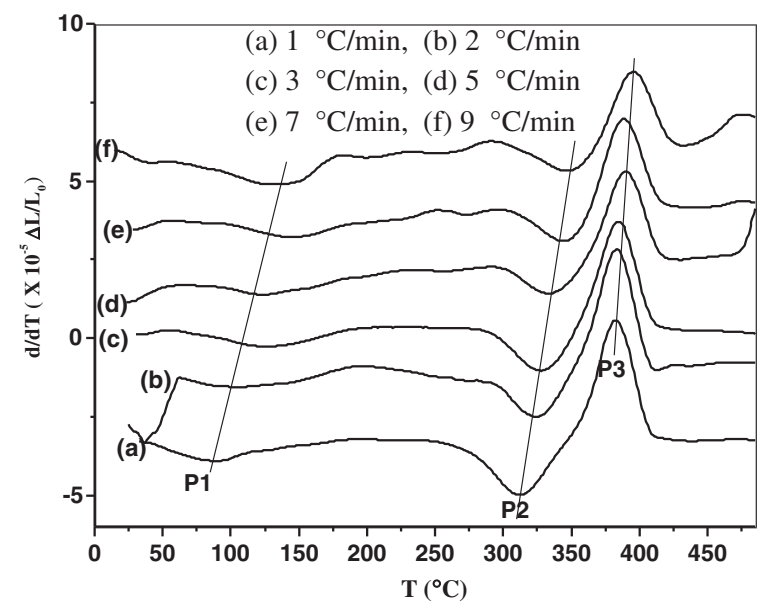

Fig. 4 Differential dilatometric heating curves of samples homogenised $1 \mathrm{~h}$ at $500^{\circ} \mathrm{C}$ and water quenched then heated with different rates.

and $30^{\circ}$ C. $\min ^{-1}$ and for dilatometer: $v=1,2,3,5,7$, and $9^{\circ} \mathrm{C} \cdot \mathrm{min}^{-1}$ ) leads practically to the same effects and anomalies (Figs. 3 and 4); in addition to the effects corresponding to the formation of $\mathrm{Cu}_{3} \mathrm{Au}$ ordered (P2) and $\mathrm{A} 1$ disordered (P3) phases, the presence of P1 at lower temperature (exothermic peak and contraction in DSC and dilatometric curves respectively), shows always the occurring of one phase transition at this temperature range. 


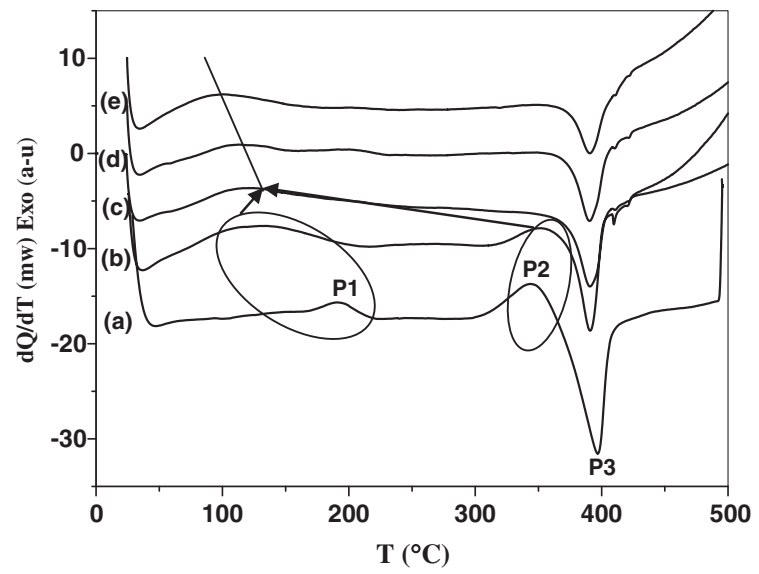

Fig. 5 DSC heating curves of $\mathrm{Cu}_{3} \mathrm{Au}$ alloy homogenised $1 \mathrm{~h}$ at different temperatures: $450^{\circ} \mathrm{C}(\mathrm{a}), 500^{\circ} \mathrm{C}(\mathrm{b}), 700^{\circ} \mathrm{C}(\mathrm{c}), 750^{\circ} \mathrm{C}$ (d) and $800^{\circ} \mathrm{C}(\mathrm{e})$ and quenched.

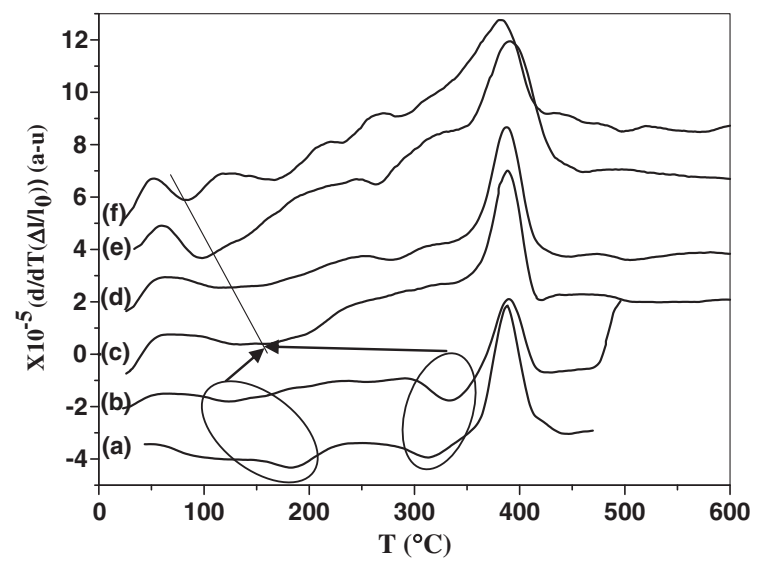

Fig. 6 Differential dilatometric heating curves of $\mathrm{Cu}_{3} \mathrm{Au}$ alloy homogenised $1 \mathrm{~h}$ at different temperatures: $450^{\circ} \mathrm{C}(\mathrm{a}), 500^{\circ} \mathrm{C}(\mathrm{b}), 700^{\circ} \mathrm{C}(\mathrm{c}), 750^{\circ} \mathrm{C}$ (d), $800^{\circ} \mathrm{C}$ (e) and $850^{\circ} \mathrm{C}$ (f) and quenched.

All these effects shift toward the higher temperature with the increase of heating rate. Such behaviour is easy to understand by referring to the transformation mechanism. The total number of vacancy jumps taking place during heating up to a fixed temperature is higher when the heating rate is lower. ${ }^{13)}$

\subsection{Homogenisation temperature effect}

The variation of the homogenisation temperature from $450^{\circ} \mathrm{C}$ to $800^{\circ} \mathrm{C}$ gives the same anomalies in DSC and dilatometric curves (Figs. 5 and 6): the three peaks P1, P2 and P3 (two exothermic and one endothermic peaks in DSC curves and two contractions and an important expansion in dilatometric curves); the first unknown one at lower temperature and two others corresponding to the $\mathrm{Cu}_{3} \mathrm{Au}$ ordered and A1 disordered phases formation, exist for the samples homogenised at temperatures below $700^{\circ} \mathrm{C}$. However, starting from this latter temperature, one can see the rearrangement of P1 and P2 and the obtaining of only one peak, which can be explained by the disappearance of one of them or their overlapping.

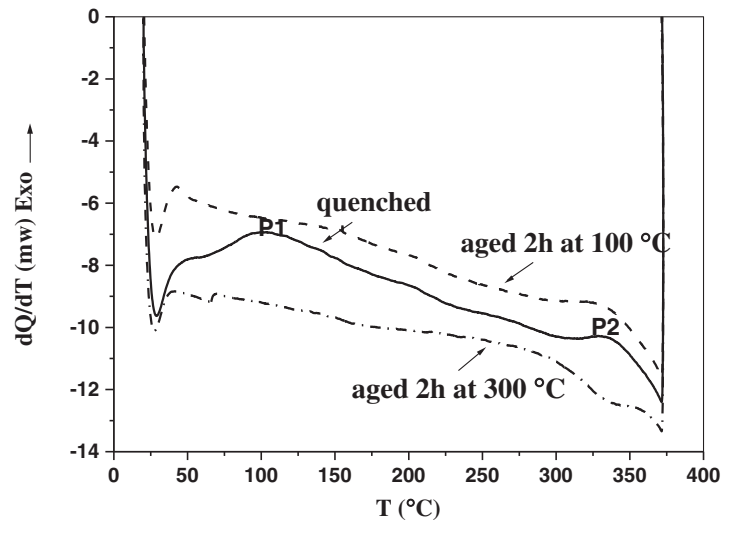

Fig. 7 DSC heating curves of $\mathrm{Cu}_{3} \mathrm{Au}$ alloy for different states.

However, the obtained effects shift towards lower values of temperature when the homogenisation temperature increases because of the increase of non-equilibrium (quenched-in vacancies) concentration which improves the diffusion process.

So, one can note that the two analyses show always the presence of effect or anomaly $\mathrm{P} 1$ with various heating rate and homogenisation temperature.

\subsection{Annealing state}

The previous results give idea to study some annealing states and to follow the temperature peaks of the effects found by DSC. Thus samples are annealed at $100^{\circ} \mathrm{C}$ and $300^{\circ} \mathrm{C}$ during $2 \mathrm{~h}$; obtained DSC results are shown in Fig. 7. As P1 appears at low temperature, the study has been restricted to the temperature interval $\left[20-400^{\circ} \mathrm{C}\right]$.

Compared to the quenched state, the annealing of $2 \mathrm{~h}$ at $300^{\circ} \mathrm{C}$ leads to the disappearance of the two peaks P1 and P2. The absence of P2 is certainly due to the complete transformation of the disordered phase to the antiphase domain of $\mathrm{Cu}_{3} \mathrm{Au}$ ordered phase during this annealing. The main question is about the absence of P1 which is probably attributed to the same phase transformation having a relation with $\mathrm{Cu}_{3} \mathrm{Au}$ ordered phase formation because $\mathrm{P} 1$ would appear during heating in DSC, if these phases $\left(\mathrm{Cu}_{3} \mathrm{Au}\right.$ ordered phase and that corresponding to P1) were independent.

\subsection{X-ray diffraction XRD study}

Although DSC and dilatometry results reveal the existence of the new peak around $100^{\circ} \mathrm{C}$, the XRD study of the alloy homogenised $1 \mathrm{~h}$ at $500^{\circ} \mathrm{C}$ and heated up to $100^{\circ} \mathrm{C}$ shows no new peaks (Fig. 8(b)) in comparison with the obtained spectrum of quenched state (Fig. 8(a)) which corresponds to the A1 disordered state. The peaks which are marked by an asterisk indicate the presence of copper oxide.

This behaviour can be explained by the kind of transition kinetic in this alloy which is slow. It is the case of the $\mathrm{Cu}_{3} \mathrm{Au}$ ordered phase; the obtained XRD spectrum of the $\mathrm{Cu}$ 50 mass $\%$ Au alloy homogenised and heated up to $300^{\circ} \mathrm{C}$ (Fig. 9(a)) shows no peaks corresponding to the $\mathrm{Cu}_{3} \mathrm{Au}$ ordered phase. The spectrum corresponding to the $\mathrm{Cu}$ 50 mass $\%$ Au alloy homogenised and annealed $1 \mathrm{~h}$ at $300^{\circ} \mathrm{C}$ 

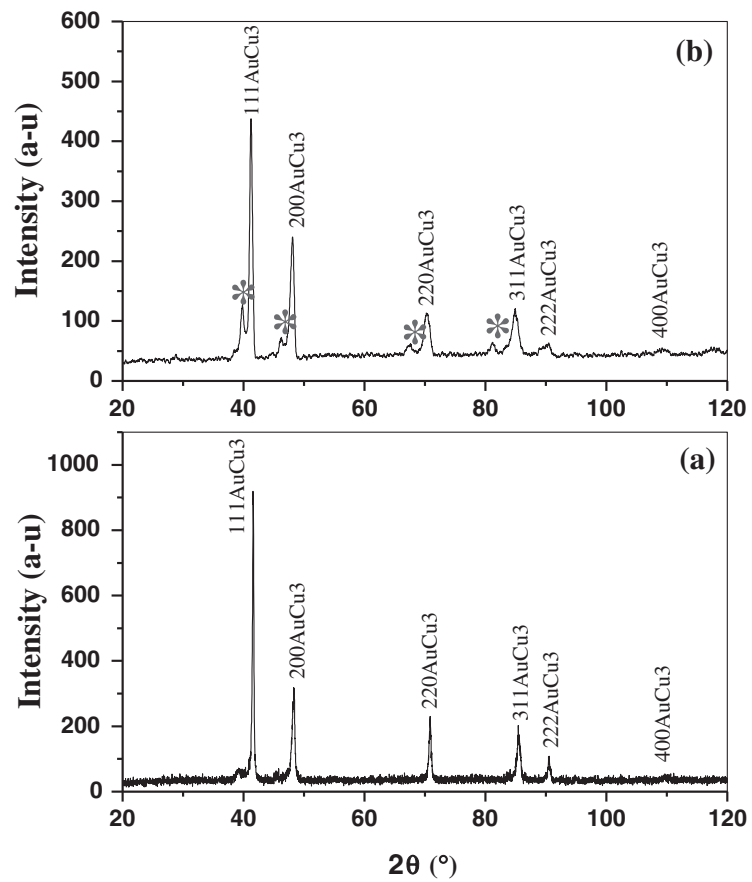

Fig. 8 X-ray diffraction patterns of the $\mathrm{Cu}_{3} \mathrm{Au}$ homogenised $1 \mathrm{~h}$ at $500^{\circ} \mathrm{C}$ and quenched (disordered state) (a), then heated up to $100^{\circ} \mathrm{C}$ (new reaction) (b).

(Fig. 9(b)) also shows no peaks of $\mathrm{Cu}_{3} \mathrm{Au}$ ordered state, nevertheless the DSC and dilatometry studies of this alloy reveal the complete formation of $\mathrm{Cu}_{3} \mathrm{Au}$ phase after $1 \mathrm{~h}$ at $300^{\circ} \mathrm{C}$. The appearance of the different peaks of $\mathrm{Cu}_{3} \mathrm{Au}$ ordered state is obtained only for a long annealing time when the order degree of this phase becomes higher, as it is shown in Fig. 9(c) for the $\mathrm{Cu}-50$ mass\% Au alloy annealed for $40 \mathrm{~h}$ at $300^{\circ} \mathrm{C}$.

\subsection{High resolution transmission electron microscope (HRTEM) study}

Figure 10 shows a (110)* electron diffraction pattern of $\mathrm{Cu}-50$ mass\% $\mathrm{Au}$ alloy homogenised $1 \mathrm{~h}$ at $500^{\circ} \mathrm{C}$ and water quenched then heated up to $100^{\circ} \mathrm{C}$. On this diffraction pattern the strong spots $((000),(\overline{2} 20),(2 \overline{2} 0),(002),(00 \overline{2}),(1 \overline{1} 1)$, $(\overline{1} 11),(1 \overline{1} \overline{1}),(\overline{1} 1 \overline{1}))$ are attributed to the disordered phase of FCC structure and the weak spots $((001),(00 \overline{1}),(\overline{1} 10),(1 \overline{1} 0))$ are attributed to the superlattice reflections where atoms are arranged in the form of a structure having periodicity, but there is some weak spots which are not indexed (marked with (?)). These spots can be attributed to this new reaction detected before by DSC and $\mathrm{DI}_{24}$.

A HRTEM image of $\mathrm{Cu}-50$ mass \% Au alloy homogenised for $1 \mathrm{~h}$ at $500^{\circ} \mathrm{C}$, then heated up to $100^{\circ} \mathrm{C}$ is represented in Fig. 11. This latter shows the cross of two different directions corresponding to the directions observed in SAED in Fig. 10.

\subsection{Electrical resistivity measurements}

It is well known that any form of disorder in metallic structure, e.g. impurities, dislocations or point defects will make a large contribution to the electrical resistance. ${ }^{14,15)}$ Accordingly, superlattices below Tc (the critical temperature
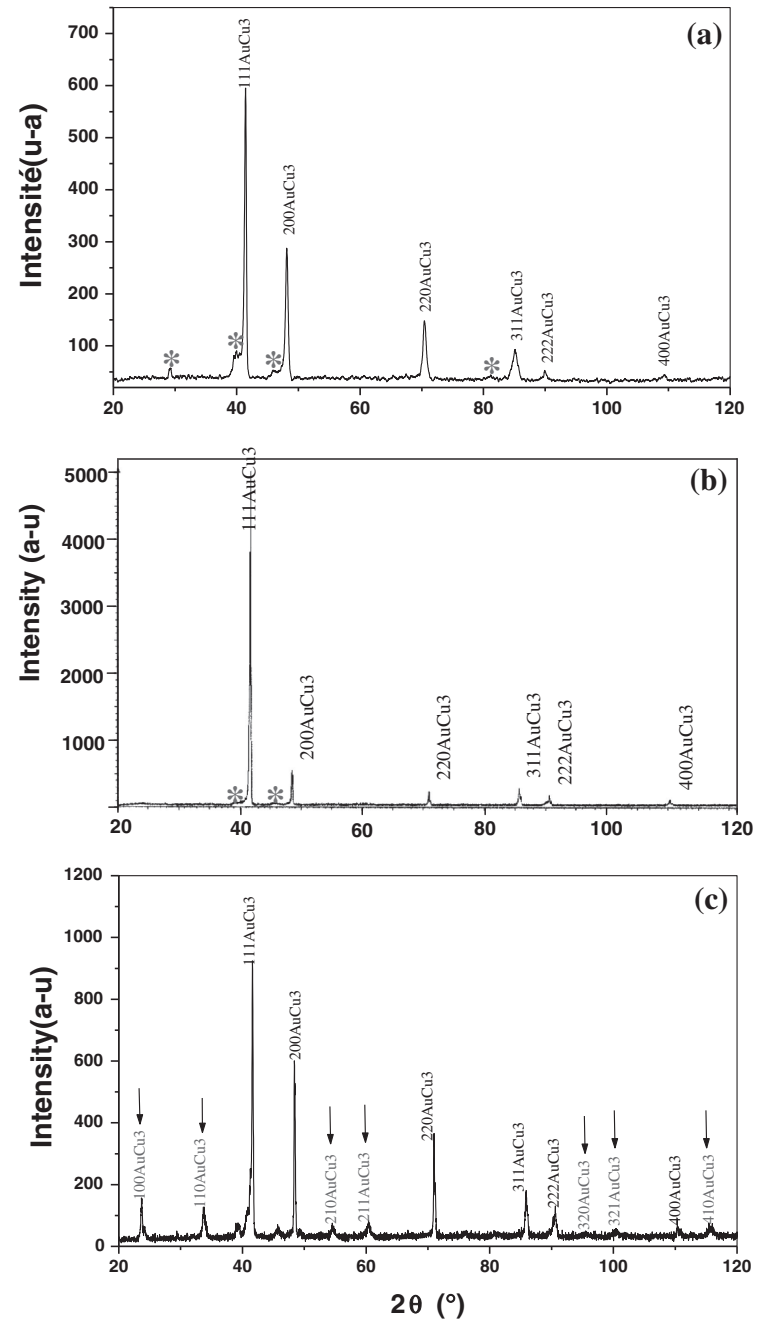

Fig. 9 X-ray diffraction patterns of the $\mathrm{Cu}_{3} \mathrm{Au}$ homogenised for $1 \mathrm{~h}$ at $500^{\circ} \mathrm{C}$ and quenched then heated up to $300^{\circ} \mathrm{C}$ (a), annealed $1 \mathrm{~h} \mathrm{(b)} \mathrm{and} 40 \mathrm{~h}$ (c) at $300^{\circ} \mathrm{C}$.

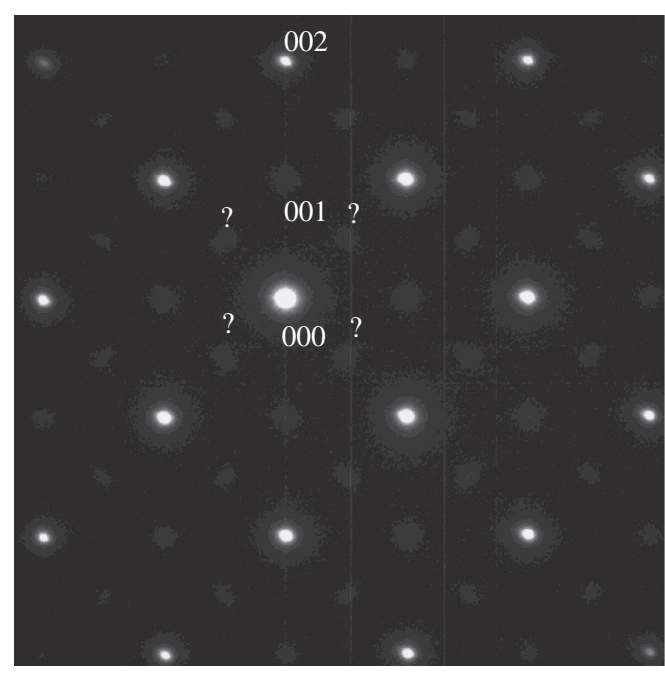

Fig. $10[100]$ electron diffraction pattern of the $\mathrm{Cu}_{3} \mathrm{Au}$ alloy homogenised $1 \mathrm{~h}$ at $500^{\circ} \mathrm{C}$ and heated up to $100^{\circ} \mathrm{C}$.

of order-disorder transition) have a low electrical resistance, but a temperature rising increases the resistivity. ${ }^{15)}$ The obtained results are shown in Table 1. 


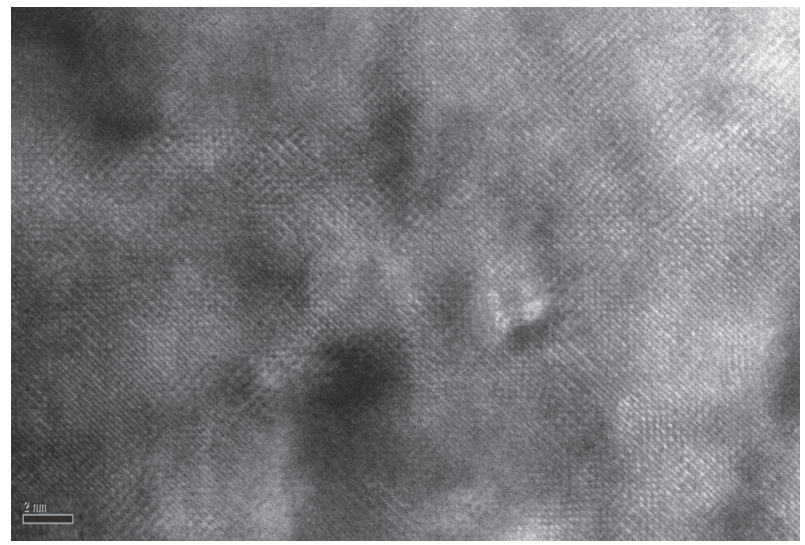

Fig. 11 HRTEM image of the CuAu alloy homogenised $1 \mathrm{~h}$ at $500^{\circ} \mathrm{C}$, heated up to $100^{\circ} \mathrm{C}$ and quenched.

Table 1 Electrical resistivity measurements of $\mathrm{Cu}_{3} \mathrm{Au}$ alloy for different states.

\begin{tabular}{ll}
\hline \multicolumn{1}{c}{ treatment } & $* 10^{-3} \rho(\Omega . \mathrm{cm})$ \\
\hline heated up to $100^{\circ} \mathrm{C}$ & $0.07 \pm 0.014$ \\
heated up to $300^{\circ} \mathrm{C}$ & $0.07 \pm 0.017$ \\
homogenised $1 \mathrm{~h}$ at $500^{\circ} \mathrm{C}$ & $0.0021 \pm 0.0056$
\end{tabular}

It is evident to have the resistivity value of the quenched (disordered) alloy higher than that in $\mathrm{Cu}_{3} \mathrm{Au}$ ordered phase. But one can note that the resistivity of a sample heated up to $100^{\circ} \mathrm{C}$ has the same value as in quenched (disordered) alloy, so this new reaction can be attributed to the formation of a periodic antiphased (PAP) structure with stacking faults.

\subsection{Microhardness measurements}

The ordering often produces a change of crystal structure and leads to hardening. The $\mathrm{Cu}_{3} \mathrm{Au}$ crystals have a lower yield stress when it is well ordered than when it is only partially ordered. Experiments show that such effects can be accounted for if the maximum strength, as a result of ordering, is associated with a critical domain size, ${ }^{14)}$ i.e. the hardness increases with antiphase domain growth until a critical size than decreases with the process of coalescence of the antiphase domain boundaries (APDB). In our case, the microhardness of quenched (disordered) alloy equals to $102 \pm 2 \mathrm{~N} . \mathrm{mm}^{-2}$ and the ordering of $\mathrm{Cu}_{3} \mathrm{Au}$ phase leads to its increase until $122 \pm 5 \mathrm{~N} \cdot \mathrm{mm}^{-2}$ (Table 2).

For the sample heated up to $100^{\circ} \mathrm{C}$, the microhardness equals to $86 \pm 5 \mathrm{~N} . \mathrm{mm}^{-2}$; this result indicates that the first peak is attributed to a low ordered phase, which may be a transitory phase with some periodic antiphased structure.

\subsection{Kinetics analysis based on non isothermal DSC tests}

It is well known that the isoconversion methods are the most reliable methods for the calculation of activation energies of thermally activated reactions. A large number of these methods have been proposed in the literature. For this study, we have chosen the Starink method ${ }^{16)}$ because it has the best accuracy, combined with a simple application; it has the following form:
Table 2 Microhardness of the different phases in $\mathrm{Cu}_{3} \mathrm{Au}$ alloy.

\begin{tabular}{cccc}
\hline type of phase & new phase & $\mathrm{Cu}_{3} \mathrm{Au}$ phase & $\begin{array}{c}\text { disordered } \\
\text { phase }\end{array}$ \\
\hline $\mathrm{H}_{\mathrm{v}}\left(\mathrm{N} \cdot \mathrm{mm}^{-2}\right)$ & $86 \pm 5$ & $122 \pm 5$ & $102 \pm 2$ \\
\hline
\end{tabular}

Table 3 Activation energy $E_{\text {act }}$ and Avrami exponent $n$ values of the different phases formation in $\mathrm{Cu}_{3} \mathrm{Au}$ alloy.

\begin{tabular}{llll}
\hline \multicolumn{1}{c}{ type of phase } & $\begin{array}{c}\text { new phase } \\
(\mathrm{P} 1)\end{array}$ & $\begin{array}{c}\mathrm{Cu}_{3} \mathrm{Au} \text { phase } \\
(\mathrm{P} 2)\end{array}$ & $\begin{array}{c}\text { disordered } \\
\text { phase }(\mathrm{P} 3)\end{array}$ \\
\hline$E_{\text {act }}\left(\mathrm{KJ}^{\prime} \mathrm{mol}^{-1}\right)$ & $94 \pm 7$ & $296 \pm 16$ & $1659 \pm 46$ \\
$\mathrm{n}$ & $1.23 \pm 0.09$ & $1.04 \pm 0.09$ & $0.81 \pm 0.16$ \\
\hline
\end{tabular}

$$
\ln T_{\mathrm{p}}^{1.92} / V=\left(1.0008 E_{\text {act }} / R T_{\mathrm{p}}\right)+\mathrm{const}
$$

where $V$ is the heating rate, $T_{\mathrm{p}}$ is the peak temperature observed in DSC curves and $R$ is the perfect gas constant.

For isothermal treatments where the temperature is constant (the chosen temperature is $130^{\circ} \mathrm{C}$ ), it will be easy to obtain the Avrami exponent $n$ from the following equation: ${ }^{17)}$

$$
\ln \left[\ln (1-\alpha)^{-1}\right]=-n \ln V+\text { const }
$$

where $\alpha$ represents the transformation fraction.

The calculated activation energies $E_{\text {act }}$ and Avrami exponent $n$ are summarised in Table 3. The obtained activation energy values show that the formation of disordered phase requires a higher energy which means that the order-disorder transition in this alloy is the first order. For the first reaction, the value of $E_{\text {act }}$ is lower than that of $\mathrm{Cu}_{3} \mathrm{Au}$ ordered phase. These results are reasonable if we take in consideration that this first reaction corresponds to a modulated structure with long periodicity i.e. the first reaction is less ordered than $\mathrm{Cu}_{3} \mathrm{Au}$ because of the presence of defects as stacking faults. But concerning the $n$ values, one can observe that $n$ is lower in disordered state because of the type of order-disorder transformation in this alloy, which is very weak due to the existence of four kinds of antiphase domains in this lattice, and that $n$ corresponding to the transition from disordered phase to this new phase is higher, which means that this transformation is rapid.

\section{Conclusion}

In the present study, we have followed the all possible phase transition in the binary intermetallic $\mathrm{Cu}_{3} \mathrm{Au}$ alloy. We first detected a new reaction at low temperature range before the $\mathrm{Cu}_{3} \mathrm{Au}$ ordered phase formation by differential scanning calorimetry (DSC) and dilatometry. Then we confirmed the existence of this new reaction at different heating rates during the non isotherm tests by the two methods.

We have found the same anomalies for sample homogenised at various temperatures and starting from $700^{\circ} \mathrm{C}$, the first effect and that of $\mathrm{Cu}_{3} \mathrm{Au}$ ordered phase are rearranged and give only one; thus the annealing of $2 \mathrm{~h}$ at $300^{\circ} \mathrm{C}$ leads to conclude that these two effects are probably dependents.

The XRD study reveals that the kinetic of the different transitions in this alloy are slow. 
The electron diffraction pattern and a HRTEM image for alloy homogenised $1 \mathrm{~h}$ at $500^{\circ} \mathrm{C}$ then heated up to $100^{\circ} \mathrm{C}$ are indicative of the presence of ordered phase having a periodic structure.

A detailed analysis of this new reaction by calculation of different parameters: the resistivity $\rho=0.0021 .10^{-3} \Omega . \mathrm{cm}$, the microhardness $H v=86 \mathrm{~N} \cdot \mathrm{mm}^{2}$, the activation energy $E_{\text {act }}=94 \mathrm{KJ}_{\mathrm{mol}}{ }^{-1}$ and the Avrami exponent $n=1.23$, confirms the presence of this new reaction.

\section{Acknowledgements}

The authors like to express their sincere thanks to Régis RAVELLE-CHAPUIS, Application Manager, JEOL (EUROPE) SAS, for assistance with the HRTEM analysis.

\section{REFERENCES}

1) L. Guillet: Précis de métallographie, (Edition Masson \& Cie, Paris, 1958) pp. 45-49.

2) P. Papon, J. Leblond and H. E. Meijer: Physique des transitions de phases, (Dunod, Paris, 1999) pp. 212-373.

3) D. G. Papageorgiou, Ch. E. Lekka and G. A. Evangelakis: Appl. Surf. Sci. 219 (2003) 64-73.

4) F. L. Castillo Alvadaro, A. Sukiennicki, L. Wojtezak and I. Zasada: Phisica. B 344 (2004) 477-488.

5) P. Scardi and M. Leoni: Acta. Mater. 53 (2005) 5229-5239.

6) A. Tadich, L. Broekman, J. Riley, R. Leckey, S. Homolya, A. E. Smith, T. Seyller, K. Emtsev and L. Ley: J. Elspec. 144 (2005) 515-518.

7) R. Oguma, T. Eguchi, S. Matsumura and S. K. Son: Acta. Mater. 54 (2006) 1533-1539.

8) V. G. Mazauric: J. Computer-Aided. Mater. Des. 4 (1997) 113-132.

9) C. S. Barret and T. B. Massalski: Structure of Metals, (Graw-Hill Book company, New York, 1966).

10) D. Hamana, L. Amiour and L. Chetibi: Phase Trans. 82 (2009) 755766.

11) Ch. E. Lekka, N. Bernstein, M. J. Mehl and D. A. Papaconstantopoulos: Appl. Surf. Sci. 219 (2003) 158-166.

12) T. Van Hoof and Marc Hou: J. Appl. Surf. Sci. 226 (2004) 94-98.

13) B. Sprusil and B. Chalupa: J. Mater. Sci. Eng. A 324 (2002) 58-61.

14) G. Benard, A. Mechel and Talbop: Métallurgie générale, (Masson, Paris, 1969) pp. 61-62.

15) RE. Smallman: Modern Physical Metallurgy, (third Ed., Butterworth, East Kilbride, Scotland, 1970) pp. 160-163.

16) M. J. Starink: J. Thermochim. Acta 288 (1996) 97-104.

17) K. Matusita and S. Sakka: J. Noncrysol. 38-39 (1980) 741-746. 